\title{
O campo da fotografia profissional no Brasil*
}

\author{
The Field of Professional \\ Photography in Brazil
}

\author{
MARIA BEATRIZ R. DE V. COELHO \\ Doutora em Sociologia/USP. Profa. Depto de Sociologia e Antropologia/ UFMG \\ Av. Antonio Carlos 2267, $4^{\circ}$ andar - Belo Horizonte, MG. Cep. 31270-901
}

\begin{abstract}
RESUMO Este artigo procura traçar um panorama do campo da fotografia profissional no Brasil desde o primeiro governo Vargas até o final do século XX. Nas décadas de 1930 e 1940, nova leva de fotógrafos estrangeiros se mudou para o país. Alguns ocuparam postos no governo federal e construíram a imagem fotográfica da Nação. Em meados do século, a maneira de se fazer fotografias para a imprensa sofreu profunda alteração e pela primeira vez um museu brasileiro expôs fotografias. A ditadura militar interferiu decisivamente na produção da indústria cultural. Os anos de 1970 foram marcados pela transformação no perfil profissional e do status dos fotógrafos, causados principalmente pela entrada no mercado de jovens saídos das universidades. Nesta mesma década foi criada uma instituição destinada a valorizar a fotografia brasileira em todas as suas dimensões: o Núcleo de Fotografia da Fundação Nacional de Arte. Finalmente, o campo da fotodocumentação recebeu um
\end{abstract}

Artigo recebido em 27/11/2005. Autor Convidado. 
forte impulso com a criação de bolsas e de leis de incentivo que, ao lado de um aumento significativo do mercado consumidor de livros de fotografia, permitiu a multiplicação não só de trabalhos autorais, como também de publicações.

Palavras-chave Fotografia, Imprensa, Leis de Incentivo

ABSTRACT This article draws an overview of the field of professional photography in Brazil since the first Vargas administration to the end of the Twentieth Century. In the 30's and 40's, a new host of photographers came to live in Brazil from various countries. Some of them took positions in the Federal Government and were responsible for building a photographical image of the Nation. In the middle of the Century, the technique to make photos for newspapers suffered a profound change and, for the first time, a Brazilian museum organized an exhibit of photographs. The military dictatorship decisively interfered in the cultural industry. The 70's were marked by changes in the status and in the professional profile of photographers, brought about especially by young professionals pouring from universities into the field. It was at that time that came to life an institution devoted to the promotion of Brazilian photography in all its dimensions: The Photography Center of the National Foundation for the Arts. Finally, it will be shown how the field of photo documentation was boosted after the introduction of fellowships and legal incentives, which, together with a significant increase in the consumption of photography books, contributed to the growth of authorial works, as well as of publications.

Key words Photographers, press, legal incentives

A fotografia é produto da Modernidade. Como tal, ela sempre teve seu lugar de disseminação: os centros urbanos. Da Revolução de 1930 até os nossos dias o país passou por mudanças profundas. O Brasil da década de 1930 ainda tinha a maioria de sua população vivendo no campo. As cidades cresciam, ampliando e diversificando as oportunidades de trabalho para os fotógrafos. No fim do século, o país é eminentemente urbano. A fotografia, enquanto prática social também passou por várias transformações ao longo desse período. Neste artigo, procurei esboçar a história recente do campo da fotografia profissional no Brasil. Meu objetivo foi ajudar a iluminar o lugar social de onde as fotografias foram tiradas por profissionais atuantes no país, principalmente na segunda metade do século XX. Este lugar passou por transformações que têm relação não só com questões ligadas ao próprio campo da fotografia, 
mas também com questões políticas, econômicas, tecnológicas e culturais.

No início do século XX, no Brasil, a atividade fotográfica era bem estratificada. De modo geral, os profissionais não tinham um status muito elevado. Membros da burguesia e da pequena burguesia ascendente, aficionados pela fotografia, eram, em sua totalidade, diletantes que se reuniam nos fotoclubes. Lá, trocavam informações, promoviam exposições e passeios fotográficos. Buscavam, como seus pares europeus e norte-americanos, dar status de arte à fotografia. ${ }^{1}$

Dentre os profissionais, existiam poucos fotógrafos que trabalhavam para a imprensa e um número expressivo nas casas comerciais onde, além da revelação de fotografias e da venda de produtos e equipamentos fotográficos, produziam cartões-postais, retratos, fotos de casamentos e famílias, documentação do andamento de obras públicas, paisagens e outros serviços encomendados por terceiros.

Durante o primeiro governo de Getúlio Vargas, vários fatores influíram para uma mudança no campo da fotografia no Brasil. Entre eles se destacam a abertura de vagas para fotógrafos nos recém-criados órgãos do governo federal, a chegada de uma nova leva de imigrantes vindos da Europa para escapar da guerra e das perseguições políticas e étnicas de regimes autoritários, e as transformações no formato dos jornais e revistas brasileiros que, após a II Guerra Mundial, trocaram a influência francesa pela norte-americana.

\section{Estado e fotografia: imagem da nação}

Os ministérios e órgãos federais criados durante o Estado Novo abriram um novo campo de trabalho para intelectuais e trabalhadores especializados, inclusive para fotógrafos e cinegrafistas. Ocupando estes espaços, foram na maioria os estrangeiros, muitos deles recém-chegados ao país, que se encarregaram de construir a imagem fotográfica e cinematográfica do Brasil nesse período, trabalhando em instituições públicas, ou na imprensa.

A Seção de Estudos do Serviço de Proteção ao Índio (SPI) tinha em seus quadros os fotógrafos e cinegrafistas Harald Schultz (1909-1966) e Heinz Foerthmann (1915-1978), responsáveis pela documentação de aldeias contatadas na década de 1940. Em 1939, Harald Schultz passou a trabalhar na Seção de Estudos do SPI e, alguns anos depois, o Serviço teve seus quadros reforçados com a contratação de Heinz Foerthmann. Em meados dos anos de 1940, Harald Schultz deixou o SPI e mudou-se

Sobre o assunto ver: COSTA, Helouise e RODRIGUES, Renato. A fotografia moderna no Brasil. Rio de Janeiro: Editora da UFRJ/ IPHAN/ Funarte, 1995. 
para São Paulo, onde se tornou assistente de Herbert Baldus, depois de, a seu convite, ser aluno do curso de etnologia brasileira na Escola de Sociologia e Política. Escreveu vários artigos sobre lendas, costumes e vocabulários de nações indígenas que foram publicados não só no Brasil mas também no exterior. A maior parte de suas fotografias e filmes estão hoje no Museu do Índio e no Museu de Arqueologia e Etnologia da Universidade de São Paulo. Heinz Foerthmann, alemão de Hannover, depois de deixar o SPI e passar uma temporada nos Estados Unidos, chamado por Darcy Ribeiro, com quem trabalhara na instituição, tornouse professor na Universidade Nacional de Brasília.

O Serviço do Patrimônio Histórico e Artístico Nacional foi outro local onde a fotografia passou a ser valorizada. Os intelectuais do SPHAN, sob o comando de Rodrigo de Melo Franco de Andrade, fizeram um amplo trabalho de documentação do que consideravam o patrimônio nacional, para justificar seu tombamento. ${ }^{2}$ Para tanto, consultavam e colecionavam documentos que atestavam o valor do bem a ser tombado, e completavam seu trabalho produzindo desenhos e fotografias. A Revista do Patrimônio, órgão de divulgação do trabalho dos intelectuais do SPHAN, desde o seu primeiro número, trouxe várias fotografias. Na Revista do Patrimônio 6, lançada em 1953, foi publicado o trabalho pioneiro de Gilberto Ferrez intitulado A fotografia no Brasil. Neto do fotógrafo Marc Ferrez, Gilberto dedicou toda a sua vida ao estudo da fotografia brasileira e foi autor de várias obras sobre o tema. No artigo, o autor chamou a atenção para o valor da fotografia como documento histórico, e convocou a todos os que possuíssem imagens de cidades, prédios, fazendas, engenhos, paisagens do século XIX, para entrarem em contato com "museus, bibliotecas, arquivos públicos e especialmente a diretoria do Patrimônio Histórico e Artístico Nacional, a fim de que se possa empreender o levantamento de quanto ainda existe". ${ }^{3}$

No início dos anos de 1940, o SPHAN passou a contar com o trabaIho de Marcel Gautherot. Nascido em Paris, em 1910, Gautherot formouse na École des Arts Décoratifs. Participou da montagem de exposições e chegou a fazer uma viagem ao México para o Museu do Homem de Paris. Em 1940, estabeleceu-se no Rio de Janeiro, onde conheceu Rodrigo Melo Franco de Andrade, que o levou para o SPHAN. Gautherot se identificou completamente com os modernistas do SPHAN. Através dele,

2 Sobre o assunto, ver SANTOS, Mariza Veloso Motta. "Nasce a academia do SPHAN". In: ARANTES, Antonio Augusto (org.) Revista do Patrimônio: Cidadania, Rio de Janeiro: IPHAN, vol.24, p.77-95,1996.

3 FERREZ, Gilberto. A fotografia no Brasil. O texto foi publicado novamente In: CAMPOFIORITO, Ítalo (org.) Revista do Patrimônio: 60 anos: a revista. Rio de Janeiro: IPHAN, vol.26, p.294-355, 1996. O texto citado está na p. 294. 
manteve a ligação com a arquitetura e o design e também com a fotografia, além do prazer de viajar. Por dez anos foi fotógrafo da instituição, realizando uma ampla documentação do patrimônio arquitetônico do país e do trabalho de Niemeyer, de quem se tornou grande amigo e o principal fotógrafo de sua obra, na opinião do arquiteto.

Gautherot foi colaborador da revista O Cruzeiro e publicou fotos em livros e nas principais revistas européias. No final dos anos de 1950, participou da Campanha de Defesa do Folclore Brasileiro, fazendo uma série de fotografias para documentar os folguedos populares. ${ }^{4} \mathrm{O}$ movimento tinha como objetivo a catalogação e proteção das festas populares tradicionais. Deixou um arquivo de mais de 30.000 negativos sobre o país, que se encontra no acervo do Instituto Moreira Salles. Também fez mais de 50 filmes documentários sobre o Brasil. Em 1964 publicou o primeiro de seus 14 livros de fotografia sobre o país. O fotógrafo morreu em 1996.

Outro órgão a contratar o trabalho dos fotógrafos foi o Departamento de Imprensa e Propaganda — o DIP. Foi na produção de bens culturais e na promoção da cultura nacional que a fotografia foi mais utilizada. A Divisão de Divulgação tinha um Serviço de Edições e Revisão Geral que contava com uma redação própria, responsável pelo boletim O Brasil de hoje, de ontem e de amanhã (editado de 1940 a 1944) e outras publicações. Em 1944 passou a produzir a revista Brasil Reportagens, "com abundante material fotográfico e trabalhos sobre todas as atividades da vida nacional". 5 A instituição enviava os textos e imagens para serem reproduzidas pela imprensa nacional. Além disso, possuía "um serviço telegráfico de notícias de interesse nacional, um serviço de artigos assinados por autores nacionais e um serviço de clichês e fotografias para distribuir à imprensa brasileira e estrangeira". ${ }^{6}$

O DIP promovia exposições, mostras de arte, concertos, conferências e palestras (para a elite erudita), patrocinava festas populares, festejos cívicos, excursões turísticas a sítios históricos e pitorescos (para a massa popular); produzia filmes, livros, cartazes, folhetos, programas de rádio. Foi assim que uma nova imagem do país começou a ser delineada, e a fotografia foi parte ativa desta construção.

Entre os fotógrafos contratados para o Departamento de Imprensa e Propaganda estava Jean Manzon. Sua importância na história da fotografia brasileira é inquestionável, não só pelo período em que trabalhou

4 SEGALA, Lygia. Bumba-meu-boi Brasil. In: DE FRANCESCHI, Antonio Fernando. (apres.) O Brasil de Marcel Gautherot. São Paulo: Instituto Moreira Salles. S/d. p.40-47.

5 GOULART, Silvana. Sob a verdade oficial: ideologia, propaganda e censura no Estado Novo. São Paulo: Marco Zero, 1990, p.64.

6 GOULART, Silvana. Sob a verdade oficial, p.66. 
no DIP, mas também por ser o responsável pela introdução das fotorreportagens no país, na revista $O$ Cruzeiro. ${ }^{7}$

\section{A fotografia na imprensa e nos museus}

Lançada em 1928, O Cruzeiro só contava com um fotógrafo em seus quadros, até a entrada de Jean Manzon, em 1943. Com ampla liberdade de ação, e seguindo o modelo da revista norte-americana Life, Manzon transformou a revista, mudando não apenas o estilo e o espaço ocupado pelas fotografias, mas também a própria maneira de se fazer as matérias. Investindo nas grandes reportagens, abrindo espaço para as fotografias, a revista passa a apresentar, em tom aventuresco, o Brasil para a classe média nacional. A valorização e glamurização do fotógrafo aventureiro foi uma estratégia de marketing de revistas como a americana Life e também foi utilizada em O Cruzeiro. Esta estratégia acabou por dar aos fotógrafos autonomia e respeito profissional inéditos naquele Brasil das décadas de 40 e 50. O sucesso do novo estilo da revista dos Diários Associados, empresa de Assis Chateaubriand, foi estrondoso e o prestígio de Manzon cresceu.

Pouco depois de entrar em O Cruzeiro, Manzon conseguiu a contratação de novos fotógrafos. Neste grupo se destacava José Medeiros, piauiense de família da classe média, que vencendo o enorme preconceito contra a profissão de repórter fotográfico existente no país na época, deixou de ser amador para tornar-se profissional em O Cruzeiro. ${ }^{8}$ Medeiros foi o primeiro brasileiro a publicar um livro de fotografia com intuito de documentação, sobre o candomblé da Bahia, em 1957.

Os suplementos literários dos jornais eram locais de disputas de posições entre visões diferentes sobre a identidade nacional. As revistas, principalmente a partir de O Cruzeiro, também abriram suas páginas para reportagens sobre o país. Foi assim que, num desdobramento do movimento modernista, e acompanhando de perto os temas eleitos pelos pesquisadores estrangeiros que chegaram ao país, os índios, os ritos do candomblé, a situação dos paus-de-arara, o carnaval e tantas outras questões viram temas recorrentes e merecedores de grande destaque em suas páginas. Só que, enquanto os suplementos literários eram lo-

7 Sobre a revista O Cruzeiro e a atuação de Jean Manzon na revista ver, entre outros, PEREGRINO, Nadja. O Cruzeiro: a Revolução da Fotorreportagem. Rio de Janeiro: Dazibao, 1991 e COSTA, Helouise. Um olho que pensa. Estética Moderna e Fotojornalismo. 2v. Tese de doutorado. Faculdade de Arquitetura e Urbanismo. Universidade de São Paulo. São Paulo, 1998.

8 "Graças ao Manzon o fotógrafo brasileiro conquistou um novo lugar. Antes ele era tido como um marginal que ia para festa de casamento e roubava os presentes. Fotógrafo não usava paletó, nem gravata. Era um pobre desdentado, o equipamento de péssima qualidade e o salário miserável”. Depoimento de Flávio Damm, In: MAGALHÃES, Ângela e PEREGRINO, Nadja. (Orgs.) José Medeiros 50 anos de fotografia, Rio de Janeiro: Funarte, 1986. (catálogo de exposição),.p.11. 
cais de debate, a revista divulgava um único ponto de vista, difundindo uma imagem ufanista e desenvolvimentista do país, que aparecia como possuidor de um grande potencial a ser explorado. Mesmo quando o fotógrafo tinha uma visão distinta, o conjunto de título, texto e legenda direcionavam o olhar do leitor para uma interpretação predefinida do conjunto de fotografias da matéria.

O Cruzeiro inovou não só por criar a maior equipe de fotógrafos até então existente no país (os jornais e revistas costumavam ter um ou no máximo dois profissionais na sua equipe de redação), mas também por deixar que eles formassem dupla com os repórteres com quem tinham mais afinidade, e se especializassem nos assuntos de seu interesse. No auge da revista, a equipe era composta por 30 fotógrafos, só no Rio de Janeiro. Apesar de seu sucesso e de sua valorização, até 1955 a maioria das capas eram de fotografias de estrelas do cinema - principalmente americano - e eram feitas por profissionais dos grandes estúdios. É que desde o lançamento da revista, em 1928, Chateaubriand havia feito uma permuta com o diretor, no Brasil, da já poderosa companhia americana Metro Goldwyn Mayer. Através desta permuta, um curta-metragem em que aparecia a máquina de rotogravura imprimindo exemplares do próximo número da revista era exibido antes de cada projeção de filmes da empresa cinematográfica no país, em troca da publicação regular de anúncios e matérias promovendo filmes do estúdio de cinema. Só a partir de 1955 que começam a aparecer capas com fotografias feitas pelo pessoal da casa. O tema não mudou muito: geralmente a fotografia era feita em estúdio por Ed Keffel e mostrava o rosto de uma bela mulher.

Os fotógrafos participavam ativamente das reuniões de pauta. Tinham todas as condições de trabalho disponíveis na época, podendo fretar aviões e viajar quando achassem necessário. Faziam reportagens que demandavam longas pesquisas chegando a publicá-las em capítulos (algumas duravam mais de um mês), coberturas internacionais e editavam as fotografias junto com os redatores. Tinham acesso às revistas de fotografia estrangeiras, viajavam para o exterior.

Entre os profissionais da revista, existia uma rivalidade ferrenha entre os defensores da fotografia produzida e a foto instantânea. Esta briga aparecia como a disputa entre as câmaras Rolleiflex e Leica.

A Rolleiflex usava filmes 120 de 12 chapas, que produziam os negativos de $6 \times 6 \mathrm{~cm}$ e permitem grandes ampliações com boa definição da imagem. Era uma câmara reflex de duas objetivas, sendo que uma capta a imagem que vai sensibilizar o filme e outra reflete a imagem em um vidro despolido quadriculado que é o visor. Suas características fazem com que ela produza fotografias quadradas, de boa qualidade, mas que demandam um certo tempo para que seus controles sejam regulados. $A$ Leica foi a primeira câmara fotográfica a utilizar os filmes do recém-cria- 
do cinematógrafo, sendo que enquanto o negativo deste tinha o tamanho de $16 \mathrm{~mm}$, o fotográfico tem o dobro ou seja, media $24 \times 36 \mathrm{~mm}$ (tamanho que permanece e que o cinema iria adotar anos depois) e que permitia a exposição de 36 chapas (o que dava muito mais autonomia aos repórteres fotográficos). A Leica foi revolucionária em vários aspectos: foi a primeira câmara com o corpo horizontal, totalmente construído em metal, usava obturador de cortina (silencioso e discreto) e popularizou o controle da velocidade da exposição, a alavanca de transporte do filme e o rebobinador. Além disto, tinha lentes que permitiam uma definição excelente e uma simplicidade no manejo que viabilizava a realização de fotografias em um tempo muito curto, o que ficou conhecido como 'instantâneos'. O sucesso da Leica foi enorme: no ano de seu lançamento - 1927 — foram vendidas mil câmara fotográficas, e em 1933 esse número havia subido para mais de cem mil câmaras vendidas. Apesar do sucesso entre os fotógrafos independentes principalmente da Europa e Estados Unidos, a câmara era vista com desconfiança por redatores de jornais e revistas, que a consideravam quase um brinquedo. Esta desconfiança só foi superada cerca de 10 anos depois, quando passou a ser adotada na imprensa destes países.

As características da Leica a tornavam uma câmara bem mais rápida, silenciosa e discreta do que a Rolleiflex. O lançamento do filme Tri-x, da Kodak, em 1953, potencializou as possibilidades da Leica. Muito sensível (400 asa), o Tri- $x$, que ainda hoje está no mercado, foi criado especialmente para o fotojornalismo. Sua grande latitude permite que o profissional faça fotos tanto em lugares fartamente iluminados (como um campo ao meio dia) até em lugares sombrios ou mesmo fotografias noturnas. Além disto, o filme pode ser 'puxado' (um recurso que permite trabalhar com o dobro ou até o triplo da sensibilidade original do filme compensando-se esta diferença durante a revelação). A grande vantagem do Tri-x sobre os filmes de menor sensibilidade é que ele permite que o fotógrafo dispense o uso do flash em fotografias de esportes, fotos de interior ou noturna. Com isto, além de ser possível 'congelar' um movimento muito rápido (como o momento exato do gol) e ter-se o controle da profundidade de campo, a naturalidade da cena, e a iluminação do ambiente ficam preservadas.

Negativos maiores necessitam de ampliações menores para ocupar uma página de revista, por exemplo. Isto significa que os 'grãos' 3/4 cristais de prata $3 / 4$ tendem a aparecer nas grandes ampliações feitas com filmes de $35 \mathrm{~mm}$. O mesmo pode ser dito em relação à sensibilidade do filme: quanto mais sensíveis, menos ampliações são necessárias para que os grãos apareçam. Na verdade, como a fotografia impressa é reticulada e, dado a qualidade de impressão de jornais e revistas (sendo que nas revistas costuma-se usar retículas mais finas), o filme $35 \mathrm{~mm}$ 
satisfaz perfeitamente às necessidades de ampliação destes veículos. Já a fotografia publicitária costuma utilizar câmaras que produzem fotos em formatos maiores, e filmes menos sensíveis, pois serão exibidas em cartazes e outdoors que, por serem maiores, e algumas vezes impressos em papel de melhor qualidade, exigem uma definição melhor quando ampliados. Esta é apenas uma das diferenças. Toda a composição da fotografia se modifica se ela for feita em filme quadrado em vez de um retangular.

Mas o que realmente estava em jogo era o papel do repórter fotográfico e seu direito de interferir numa cena, para torná-la mais atraente, para produzi-la. Jean Manzon, apesar de sua experiência anterior com o fotojornalismo europeu, era um dos que defendiam as fotos posadas, feitas com a câmara Rolleiflex. Embora tenha feito fama com suas fotografias ousadas como as primeiras dos Xavantes, gostava de ter o controle total de suas fotos (como um fotógrafo publicitário), interferindo não só nos gestos e pose do fotografado, como na composição e iluminação da fotografia. Como antecessor do grupo de fotógrafos da revista, impôs suas preferências como padrão, que continuaram a ser seguidos mesmo depois de sua saída, no início dos anos 50, quando Ed Keffel passou a ser o líder desta tendência.

Do outro lado estavam os fotógrafos fortemente influenciados por Cartier Bresson e Eugene Smith, partidários da luz natural e das fotografias espontâneas feitas com a Leica. Neste grupo estavam José Medeiros, Flávio Damm, Luciano Carneiro, Luís Carlos Barreto, Gheorghe Torok, João Martins e Henri Ballot. A direção da revista, a exemplo do que havia acontecido nos Estados Unidos no começo do século, proibia o uso da Leica. O almoxarifado chegou a ter ordens de só fornecer filme 120. O laboratório só tinha carretel de revelação para filme que produzisse negativo 6 × 6 . Mas os fotógrafos acabavam dando um jeito de enganar a direção.

O Cruzeiro entrou em decadência no final dos anos 50, tendo seu prestígio suplantado pela Manchete. A revista fora lançada em 1952 pelo gráfico Adolfo Bloch, e desde então fazia concorrência a O Cruzeiro, inclusive empregando alguns de seus antigos fotógrafos (Jean Manzon entre eles). Manchete inovava, publicando fotos coloridas com uma qualidade de impressão jamais alcançada pela concorrente. O centro editorial do Brasil era o Rio de Janeiro, capital da República.

Após uma rápida passagem pela Manchete, Manzon fundou uma empresa cinematográfica, que produziu, cerca de 900 documentários, a maioria sobre o Brasil. Recebeu o Leão de Ouro na Bienal de Veneza em 1966. Morreu em São Paulo no ano de 1990. José Medeiros trabalhou em O Cruzeiro até 1962. Neste ano fundou uma agência de fotografias com Flávio Damm, que também saíra de O Cruzeiro. A partir daí, dedicou-se 
à fotografia cinematográfica. Ao contrário de Jean Manzon, José Medeiros voltou-se para o cinema autoral. Trabalhou com Leon Hirszman Roberto Farias, Cacá Diegues, Nelson Pereira dos Santos, Sylvio Back, Antônio Carlos Fontoura, entre outros. Em 1979 fez seu único filme, Parceiros da aventura. Ganhou vários prêmios. Deu cursos de fotografia de cinema e expôs na Casa das Américas, em Cuba. Morreu na Itália, em 1990, deixando aos cuidados de seus filhos um acervo de 20 mil negativos.

Entre os fotógrafos estrangeiros que se estabeleceram no país entre as décadas de 1930 e 40, também se destacam Pierre Verger, Hildegard Rosenthal. Hildegard nasceu na Suíça, em 1913. Viveu em Frankfurt, onde se formou em pedagogia. Estudou com Paul Wolff, fotógrafo reconhecido mundialmente por seu pioneirismo no uso da câmara Leica. Decidida a profissionalizar-se, cursou, na mesma época, processamento fotográfico no Gaedel Institut. Logo a seguir, foi contratada como fotógrafa pela empresa Rhein Mainischer Bildverlag. ${ }^{9}$

Em abril de 1937, mudou-se São Paulo. Hildegard trabalhou na Press Information, uma pequena agência de notícias. Ciceroneados pelo amigo Lasar Segall, Hildegard e seu marido passaram a freqüentar o círculo de artistas e intelectuais da cidade, relacionando-se com Alfredo Volpi, Anatol Rosenfeld, Roger Bastide, Sérgio Milliet, Mário de Andrade e Tarsila do Amaral. Hildegard publicou fotografias em jornais e revistas como O Estado de São Paulo, Folha da Manhã, Folha da Noite, A Cigarra, Rio e Sombra. Gostava de fotografar o movimento da cidade, a rua, a gente simples do povo.

Em 1948, após o nascimento de sua primeira filha, abandonou a vida profissional. Em 1974, Walter Zanini, então diretor do Museu de Arte Contemporânea da USP, conheceu sua obra. Entusiasmado, fez a curadoria da sua primeira exposição. Foi premiada como a melhor fotógrafa na XIV Bienal Internacional de São Paulo, de 1977. Hildegard morreu em São Paulo em 1990. Seis anos depois, o Instituto Moreira Salles comprou a maior parte de seu acervo.

São Paulo de meados do século XX era uma capital cheia de vitalidade. O mais importante centro industrial brasileiro ganhava ares de metrópole, e suas elites ampliavam o investimento em cultura. ${ }^{10}$ Entre os acontecimentos importantes para a área cultural paulista estão a criação do Museu de Arte de São Paulo (o MASP), do Museu de Arte Moderna e da Bienal. A fotografia fez parte destas instituições desde o início, atra-

9 Sobre Hildegard Rosenthal ver, principalmente, DE FRANCESCHI, Antonio Fernando. (apres.) Hildegard Rosenthal Cenas Urbanas. São Paulo: Instituto Moreira Salles, s.d. (catálogo de exposição)

10 Sobre o assunto ver ARRUDA, Maria Arminda do Nascimento. Metrópole e Cultura. São Paulo no meio do século XX. Bauru/ SP: EDUSC, 2001. 
vés da participação de alguns fotógrafos fotoclubistas, entre eles Thomaz Farkas. Nascido em Budapeste, na Hungria, em 1924, Farkas veio morar em São Paulo ainda criança, em 1933. ${ }^{11}$ Sua vida sempre esteve ligada à fotografia: o pai era dono da Fotoptica, uma loja que ainda hoje presta serviços de laboratório e vende equipamentos e material ótico e fotográfico. Thomaz Farkas fotografava regularmente desde menino. Tornou-se sócio do Foto Clube Bandeirante, o mais importante da cidade, criado em 1939.

Em meados de 1940, alguns paulistas principalmente — entre eles Thomaz Farkas -, influenciados pelos fotógrafos da Bauhaus e pelas pesquisas das vanguardas dos países centrais, começaram a fazer fotografias mais ousadas, experimentais, cujo modelo era a arte abstrata. Este grupo foi pioneiro no país na exploração das possibilidades abertas ao se considerar a fotografia enquanto imagem bidimensional. Mas, mesmo entre os fotoclubistas, eles muitas vezes eram ridicularizados. Farkas e seu colega de fotoclube Geraldo de Barros montaram o laboratório fotográfico do MASP, onde revelavam as fotografias que faziam como registro das obras do acervo e davam aulas para freqüentadores da instituição. Foi lá que ele fez a primeira mostra de fotografia realizada em um museu brasileiro, em 1949.

Um ano antes fora inaugurado o Museu de Arte Moderna de São Paulo, e em 1949, o do Rio de Janeiro. A primeira Bienal de São Paulo aconteceu em 1951, inserindo a cidade no circuito artístico mundial. Amigo de Mário Pedrosa e Cicílio Matarazzo, acompanhou de perto sua criação. Estava aberto um novo espaço para a fotografia que foi ocupado por fotoclubistas, principalmente pelos abertos a experimentações, como Farkas.

Em 1950, Geraldo de Barros, que além de fotógrafo era artista plástico e gráfico, fez sua primeira exposição no MASP, a Fotoforma. Em 1952 foi a vez de German Lorca expor no MAM-SP. No ano seguinte, os fotoclubistas paulistas conseguiram uma sala para expor na II Bienal Internacional de São Paulo. O Fotoclube Bandeirantes organizou a exposição de fotografia da Bienal de 1965, quando ela passou definitivamente a fazer parte desta amostra. No início dos anos 60, Farkas foi convidado pelo arquiteto Vilanova Artigas para fazer parte de um grupo que pretendia fazer cinema como forma de participação política. Apesar do projeto ter sido abortado pela ditadura, na segunda metade da década, Farkas produziu uma série de curtas-metragem sobre o Nordeste, que ficou conhecida como Caravana Farkas. ${ }^{12}$ Montou o laboratório da Escola de

11 Sobre Tomaz Farkas, ver, entre outros, MENDONÇA, Maia. (coord.). Thomaz Farkas, fotógrafo. São Paulo: DBA, 1997.

12 Os filmes foram produzidos por Thomaz Farkas e dirigidos por Eduardo Scorel, Mauricio Cappovila, Sergio Muniz, Paulo Gil Soares e Geraldo Sarro, que foi um dos mais importantes e o principal animador para os filmes dos trabalhadores nordestinos e do nordeste. 
Comunicação e Artes da USP e foi seu professor por mais de vinte anos. Nesta instituição obteve o título de doutor, com uma tese sobre a organização de expedição para a realização de filmes documentários. Criou a galeria Fotoptica (especializada em exposições fotográficas) e a revista Atualidades Fotoptica.

Na segunda metade da década de 1940 e na década seguinte, os negros pobres e trabalhadores de Salvador foram documentados por Pierre Verger nas ruas, no trabalho e nas festas populares. Pierre Edouard Léopold Verger nasceu em Paris, em novembro de 1902. Em 1932, comprou uma câmara Rolleiflex e foi para a Córsega com o seu amigo fotógrafo Pierre Boucher, que lhe ensinou não só a manejar a câmara mas também os segredos do laboratório fotográfico. Gostou da experiência e resolveu sair pelo mundo, fotografando. Foi a Moscou depois às Antilhas e a Polinésia Francesa, muitas vezes trocando a passagem por imagens dos membros da tripulação dos navios em que viajava. ${ }^{13}$

Uma das primeiras providencias que tomou quando voltou da Polinésia, em janeiro de 1934, foi ir ao museu etnográfico. Lá retomou o contato feito meses antes com Georges-Henri Rivière, sub-diretor da instituição. O Musée d'Ethnographie du Trocadéro, criado em 1879, passava por uma nova fase, recebendo um maior apoio do governo francês, que estimulava pesquisas capazes de produzir um conhecimento sistematizado sobre os nativos das colônias. Em troca de imagens para o acervo da instituição, Verger passou a dispor do laboratório do museu. Cartas de apresentação escritas pelos etnólogos também facilitaram sua entrada nas colônias. Verger também prestava serviços para a imprensa, inclusive chegando a fazer parte de uma agência de fotógrafos. Assim conseguiu passar 15 anos viajando pelo mundo.

Pierre Verger viveu no Peru entre 1942 e 1946, fotografando para o Museu Nacional de Lima. Resolvido a vir para o Brasil, em 1946 chegou a Corumbá, no Mato Grosso. De lá foi para São Paulo onde se encontrou com Roger Bastide, que Ihe recomendou enfaticamente que fosse para Salvador. Nascia ali uma amizade e um diálogo intenso entre os maiores pesquisadores das religiões e cultura afro-brasileiros de sua época.

Em agosto de 1946, chegou a Salvador. Documentou o cotidiano do povo, suas festas, e se impressionou com a força da cultura negra. Começou a freqüentar terreiros, principalmente o Axé Opô Afonjá, de Maria Bibiana do Espírito Santo, conhecida como Mãe Senhora, onde fotografava as cerimônias, pessoas em transe e os rituais de iniciação das filhas de santo, enquanto aprofundava seus conhecimentos sobre o candomblé.

13 Sobre Pierre Verger ver, entre outros, LE BOULER, Jean-Pierre. Pierre Fatumbi Verger um homem livre. Salvador: Fundação Pierre Verger, 2002 e COELHO, Maria Beatriz R. de V. Representação visual da nação: o Brasil na lente de três franceses. São Paulo: ANPOCS. 27o encontro anual da ANPOCS, 2003. (CD-ROM). 
No ano seguinte de sua chegada, Théodore Monod, diretor do Institut Français d'Afrique Noire, de Paris, Ihe deu uma bolsa para estudar a religiosidade negra na Bahia. ${ }^{14}$ Em 1949, foi para a África, em busca da conexão entre as religiões e ritos daquele continente e do Brasil e das raízes da cultura negra baiana. Em Daomé, descobriu 112 cartas sobre o comércio clandestino de escravos entra a Bahia e a África, enviadas no século XIX por Tibúrcio dos Santos, um negreiro conhecido como Alfaiate. ${ }^{15}$ A partir daí, começou uma pesquisa sobre o tráfego de escravos. A pesquisa gerou uma tese defendida na Sorbonne em 1966, que Ihe valeu o título de doutor, mesmo tendo abandonado os estudos formais quando ainda era adolescente.

Pierre Verger tornou-se Fatumbi, que significa o renascido, mensageiro entre dois mundos (o Brasil e a África) e babalaô. Entre 1977 e 1980 deu aulas nas Universidades de Ifé (na Nigéria) e na Federal da Bahia. Em 1987, criou uma fundação que leva seu nome e é responsável por seu acervo. Verger morreu em Salvador, em fevereiro de 1996.

Os jornais Diário Carioca, Última Hora, a Tribuna de Imprensa e, mais tarde, o Jornal do Brasil, foram os primeiros diários brasileiros a trocar o modelo francês de jornalismo pelo norte-americano, na década de $1950 .{ }^{16}$ A preocupação em atingir 'as massas' do período populista, se traduziu no novo desenho de suas páginas, ampliando o tamanho e o número de fotografias. Mas em termos de jornais, o acontecimento de maior impacto na imprensa do final dos anos 50 foi a reforma do Jornal do Brasil. E a primeira modificação substancial foi exatamente a publicação de uma fotografia em sua primeira página, em março de 1957. Numa atitude pioneira no país, a partir de 1962, o JB começou a publicar fotografias identificando seus autores. A partir de então, o JB tornou-se um marco no jornalismo brasileiro, pelo destaque dado às fotografias, pelas inovações na sua diagramação (promovidas pelo artista concretista Amílcar de Castro), e por abrir espaço para os debates travados por artistas e intelectuais nos anos de 1950, 1960 e 70.

Entre o final dos anos de 1950 e 60, uma nova leva de fotógrafos se estabeleceu no país. Entre eles estavam David Zingg (que logo ocupou lugar de destaque, atuando principalmente na revista Manchete), George Love, Luigi Mamprin, Maureen Bisilliat e Claudia Andujar. As câmaras japonesas, com lentes cambiáveis e mais ágeis, depois de adotadas pelos fotógrafos do JB, substituíram as antigas Rolleiflex em todas as

14 GUARIGLIA, Ana Maria. O filho do trovão: Mário Cravo entrevista Pierre Verger. In: VERGER, Pierre. Bahia África Bahia. Catálogo de exposição. São Paulo: Pinacoteca do Estado, 1996, p.7.

15 SCHWARCZ, Lilia Katri Moritz. Verger, os olhos de Xangô . In: VERGER, Pierre. Bahia África Bahia. Catálogo de exposição. São Paulo: Pinacoteca do Estado, 1996, p.38-39.

16 Sobre o assunto, ver ABREU, Alzira Alves de (org.). A imprensa em transição: o jornalismo brasileiro nos anos 50. Rio de Janeiro: Ed. Fundação Getúlio Vargas, 1996. 
redações. O centro editorial do Brasil se transferiu para São Paulo, e a editora Abril passou a ser uma das maiores empregadoras de fotógrafos. As revistas Quatro Rodas e Realidade abriram espaço para grandes reportagens, com quase todas as fotografias feitas por fotógrafos estrangeiros, recém-chegados ao país. Investindo no trabalho de fotodocumentação, Maureen publicou vários livros de fotografia retratando seu diálogo com a literatura brasileira, principalmente de Guimarães Rosa, João Cabral de Melo Neto e Jorge Amado. No fim dos anos 60, conheceu o Xingu através dos irmãos Villas Bôas, e passou a fazer uma série de trabalhos sobre os índios que vivem no Parque. Cláudia Andujar, depois de trabalhar na Realidade, no MASP e em publicações alternativas (como o Bondinho) se dedica, desde o início dos anos 70, à documentação dos índios Yanomami. Sua ligação profunda com os índios a fez engajar-se na luta pela criação do Parque Yanomami.

Esta foi a última geração de fotógrafos estrangeiros a ocupar tantos postos na imprensa brasileira. Durante os anos 60 e 70 a situação mudou. Um dos fatores que explicam esta transformação foi a profissionalização de jovens saídos dos bancos das universidades. Nesta época, a fotografia começou a fazer parte do currículo das faculdades de comunicação, de arquitetura e de artes. Alguns alunos desses cursos começaram a ser atraídos para a profissão, que ganhava destaque nas páginas do Jornal do Brasil, da Realidade e Jornal da Tarde.

Com o apoio dos militares, a indústria cultural brasileira atingiu a maturidade entre as décadas de 60 e $70 .{ }^{17} \mathrm{O}$ mercado publicitário se expandiu e a televisão se tornou o principal veículo de entretenimento e informação. A imprensa sentiu os efeitos da concorrência e buscou alternativas para manter e conquistar novos leitores. Em 1968, a editora Abril lançou a revista Veja. O modelo era o da revista Time americana. Veja aproveitou em sua redação os jovens recém-saídos dos novos cursos de comunicação, que passaram por um curso pioneiro no país, de formação de jornalistas, dado dentro da própria empresa. Fato inédito na época, em todas as sucursais da revista existia um fotógrafo contratado. ${ }^{18}$

\section{Nova geração, novas idéias, novos direitos}

A partir de 1970, jornais e revistas da chamada imprensa alternativa (como o Coojornal, Movimento, Bondinho, De Fato, Fotochoq, Nós, MuIheres, Lampião, Extra, Realidade Brasileira) e tantos outros abriram es-

17 Sobre o assunto ver, entre outros, ORTIZ, Renato. A moderna tradição brasileira. São Paulo: Brasiliense, 1984.

18 Sobre o assunto ver, COELHO, Maria Beatriz R. de V. A construção da imagem da nação brasileira pela fotodocumentação. 2 vol. Tese (Doutorado em Sociologia). Faculdade de Filosofia, Letras e Ciências Humanas, Universidade de São Paulo: São Paulo, 2000. 
paço para a entrada de jovens fotógrafos, dando-lhes a possibilidade de divulgarem uma visão mais crítica e criativa sobre o país. Revistas da chamada 'grande imprensa' - como a Isto É, que abriu um espaço especial para os jovens fotógrafos - , foram lançadas, expandindo de forma considerável o mercado de trabalho. ${ }^{19}$ No fim da década, os jornais começaram a ser ocupados por essa nova geração. Mas o que realmente impulsionou a fotografia de imprensa e documentação foi a criação de agências de fotógrafos. Agências são cooperativas de fotógrafos. Trabalhando de forma cooperativa, eles conseguiram montar uma estrutura inacessível para cada fotógrafo isolado, com secretária, laboratorista, arquivo bem organizado, etc. Com isto, alcançaram a liberdade de pautar as matérias que consideravam importantes e publicar livros com seus trabalhos. Seu olhar para o país é um olhar crítico: denunciam as mazelas sociais, a situação dos trabalhadores do campo (na época, conhecidos como bóias-frias), a violência policial, a degradação das matas e das cidades, os podres dos políticos e poderosos. Inspirando-se no movimento negro norte-americano, fotógrafos negros como Walter Firmo, Juvenal Pereira e seus seguidores passaram a ter como tema preferencial os brasileiros negros.

Desta época em diante o mercado de trabalho se ampliou e diversificou com a contratação de fotógrafos publicitários, de moda, voltados para a produção de capas de discos, etc. A composição social dos fotógrafos mudou, e a profissão passou a atrair um grande número de adeptos das classes médias e da burguesia. Muitos deles tiveram recursos suficientes para comprar equipamentos caros e fazer cursos de fotografia no exterior, inclusive de pós-graduação.

Durante o governo do General Figueiredo, aconteceram manifestações pelo fim da censura e da ditadura, pela anistia, e pelas as eleições diretas. Greves de operários começaram no ABC paulista e se espalharam pelo país. Os fotógrafos também se organizaram, assumindo as associações de fotógrafos profissionais (Arfocs) de suas cidades que estavam totalmente amorfas até então. Num movimento articulado nacionalmente a partir de agencias independentes de fotógrafos e Arfocs, criaram uma tabela de preços mínimos para free-lancers, conseguiram o reconhecimento de alguns de seus direitos autorais, como o crédito de sua autoria em todas as fotografias publicadas, e o pagamento por cessão do direito de publicação de cada fotografia vendida pela agência de notícias a que o veículo em que trabalhavam estivesse associado.

Durante este período, o intercâmbio entre os novos fotógrafos foi intenso. Alguns começaram a editar livros de fotografia, com tiragens pe-

19 Sobre a imprensa alternativa ver, principalmente, KUCISKY, Bernardo. Jornalistas e revolucionários. São Paulo: Scritta Editorial, 1991. 
quenas e edição simples. A partir dessa época, o fotojornalismo passou a ser uma atividade exercida principalmente por pessoas com nível superior. Numa pesquisa parcial, que fiz em 1998 analisando a formação 114 dos fotógrafos profissionais que mais publicaram e participaram de exposições e se profissionalizaram no país a partir da década de 1960, constatei que 81 deles têm curso universitário, sendo que 32 são formados em comunicação ou jornalismo, 16 em arquitetura, onze em artes plásticas, três em desenho industrial, cinco em ciências sociais, doze em outras ciências humanas ou biológicas (psicologia, educação, economia, ciências biológicas), e seis em ciências exatas. ${ }^{20}$ Destes, vinte e três estudaram fotografia no exterior. A grande maioria, pelo menos em alguma época da vida, trabalhou fazendo fotografias para a imprensa. Quarenta deles se dedicavam à foto publicitária.

Para fazermos uma idéia de como este quadro é diverso do anterior, dos 37 fotógrafos que atingiram maior destaque no país a partir de 1940 e nasceram entre 1900 e 1939, sete estrangeiros e seis brasileiros têm curso superior, sendo que entre os brasileiros, quatro deles eram fotoclubistas. Dos dois brasileiros com curso universitário que fizeram da fotografia meio de vida, o único a fazer da fotografia jornalística opção profissional por um período foi arquiteto Luís Humberto Pereira.

Há uma diferença muito grande na visão de país veiculada pelos fotógrafos atuantes em meados do século e os da geração formada nos bancos das universidades. Enquanto os primeiros, muitos oriundos de lugares que passaram pelo trauma da guerra, viam e mostravam um país promissor, novo, com um povo miscigenado, um tanto quanto primitivo e afável, os segundos têm uma visão muito crítica. As cidades deixam de ser lugares de progresso para serem mostradas a partir de suas favelas, das crianças de rua, das vítimas da violência policial e do crime organizado, dos soldados da ditadura agredindo estudantes e trabalhadores. O campo deixa de ser um lugar bucólico para ser mostrado como o lugar dos bóias-frias, dos trabalhadores sem terra, do desmatamento, dos garimpeiros. Os índios deixam de ser os bons selvagens prontos para serem integrados à civilização para se diferenciarem em povos que procuram manter sua cultura e que muitas vezes têm suas terras e vidas degradadas pelo contato com o homem branco. Os negros, vistos como partes da África encravada no território nacional, começaram a ser registrados através das lentes de fotógrafos negros, que procuram valorizar as cores e a dignidade de um povo que passou pela escravidão e ainda carrega um estigma.

20 COELHO, Maria Beatriz R. de V. A construção da imagem da nação brasileira pela fotodocumentação. 
A década de 1980 foi a época áurea das agências de fotojornalistas independentes, que surgiram nas principais capitais do país. Algumas, como Angular e a F-4 de São Paulo, e a Ágil Fotojornalismo, de Brasília, mantinham contato com profissionais de várias cidades do país. Muitos iniciaram sua profissionalização através delas. O trabalho dos fotógrafos independentes ficou conhecido por sua qualidade e criatividade. Algumas agências brasileiras fizeram contatos com outras sediadas no exterior, iniciando o intercâmbio de trabalhos e pautas diretamente entre os fotógrafos. A partir dessa época, a fotografia jornalística passou a ser uma atividade exercida principalmente por pessoas com nível superior. As agências tornaram-se celeiros de fotodocumentaristas.

O desenvolvimento da publicidade brasileira ampliou as alternativas de trabalho. Além de fotografar para as agências especializadas, os fotógrafos publicitários também atendem às demandas da fotografia de moda, assim como de nus das chamadas revistas masculinas e da direção de fotografia de filmes publicitários. O que estas fotografias têm em comum é a produção sofisticada. Este é o filão mais rentável do mercado profissional e o que depende de um investimento financeiro maior, que vai desde a utilização de câmara de maior formato (mais cara do que a de $35 \mathrm{~mm}$, utilizada para o fotojornalismo), até a montagem do estúdio, com toda uma parafernália cara e requintada.

O perfil dos fotógrafos publicitários não é muito diferente do dos fotojornalistas. Aqui também se observou uma tendência crescente à entrada de profissionais saídos dos bancos das universidades. Analisando a formação de 40 dos fotógrafos publicitários atuantes no país, nascidos a partir de 1943, vê-se que 30 deles são formados em alguma universidade. Destes, 13 fizeram curso de jornalismo, dez são arquitetos, seis são formados em artes plásticas, dois em ciências exatas, um fez letras, outro ciências biológicas, outro desenho industrial e finalmente, um fez administração de empresas. Ainda há lugar para fotógrafos que aprenderam sua profissão como ajudantes em estúdios publicitários, mas como o investimento na compra do equipamento e da montagem do estúdio é bastante elevado, este ramo profissional geralmente é ocupado por pessoas que têm um alto nível socioeconômico.

Além de formar fotógrafos, as universidades também passaram a ser locais de reflexão sobre a fotografia, em seus vários aspectos. Nos cursos de pós-graduação, principalmente nas áreas de comunicação social, história, arte, arquitetura e antropologia começaram a ser produzidas dissertações e teses em que a fotografia aparece como tema principal ou como apoio para a compreensão de uma época ou grupo social.

No apagar da década de 70, a fotografia brasileira recebeu impulso com a criação do Instituto Nacional da Fotografia (Infoto) da Fundação Nacional de Arte (Funarte). A Funarte foi um dos órgãos criados a partir 
da implantação do Programa de Ação Cultural na gestão de Jarbas Passarinho (governo Médici) no Ministério da Educação e Cultura. O Setor de fotografia da Funarte começou a existir com o nome de Núcleo de Fotografia e sede no Rio de Janeiro. A mobilização dos profissionais pela valorização de seu trabalho e a importância crescente da fotografia no cenário mundial e nacional foram fundamentais para sensibilizar o governo para sua importância, que até então não haviam sido merecedora de atenção oficial. Assim, pela primeira vez no país, houve o reconhecimento da autonomia desta linguagem.

O que se pretendia com a criação do Infoto era a definição e aplicação de uma política nacional para a fotografia. A hegemonia dos fotógrafos brasileiros originários das classes média e alta, saídos dos bancos das universidades e atuantes principalmente através de agências de fotografia é uma das marcas desta instituição. Tornando seus os objetivos e reivindicações deste grupo articulado de profissionais, o Setor de Fotografia buscava identificar os fotógrafos e grupos atuantes em cada região a fim de divulgar seus trabalhos e promover o intercâmbio entre eles através de encontros, debates, exposições e publicações; estimular a produção fotográfica, abrindo canais para a formação e aperfeiçoamento fotógrafos; definir uma política de preservação que identificasse os acervos e formasse pessoal técnico especializado em sua restauração e conservação.

A partir de 1983, o Setor de Fotografia começou uma série de mostras coletivas regionais, que serviu para divulgar e mapear o trabalho de dezenas de fotógrafos de todo o país. Entre os anos de 1983 e 1989, aconteceram cinco grandes mostras regionais, nas quais participaram mais de 200 fotógrafos. ${ }^{21}$ Ao lado destas mostras, foram realizadas oito Semanas Nacionais da Fotografia, no Rio de Janeiro, Brasília, Fortaleza, Belém, Curitiba, Ouro Preto e Campinas. As semanas promoviam cursos, palestras e exposições abertas a fotógrafos de todo o país. Também foram instituídos os prêmios Marc Ferrez de Fotografia (que entre 1984 e 1998 premiou 52 projetos em várias áreas da fotografia.) e o Prêmio Nacional da Fotografia, a partir de 1995.

Na área editorial, a Funarte foi responsável pela publicação de dezenas de catálogos de exposições. Também foram lançados livros que apresentam reflexões e pesquisas sobre fotografia, como por exemplo os da coleção Luz e Reflexão. O governo Collor, ao extinguir o Instituto Nacional da Fotografia, desarticulou momentaneamente o setor, que voltou a atuar principalmente a partir da segunda metade da década de 90,

21 O I Foto Centro-oeste apresentou trabalhos de 63 fotógrafos, o I Fotonordeste de 51, o I Fotonorte de 27 e o I Foto-sudeste de 59. Nos relatórios da Funarte não constam o número de inscritos no II Prêmio Marc Ferrez de Fotografia, e por isto os dados se referem apenas a nove edições da bolsa, e não das dez realizadas. 
mas de forma bem mais tímida, antes de ser novamente extinto no segundo governo de Fernando Henrique Cardoso.

O número de trabalhos autorais cresceu enormemente a partir da criação, no Brasil, de dois programas de bolsas: o Prêmio Marc Ferrez, do Instituto Nacional da Fotografia e a Bolsa Vítae. O Prêmio Marc Ferrez foi criado na gestão de Pedro Vasquez no Infoto, em 1984, com o objetivo de financiar projetos em várias áreas da fotografia como ensaio, documentação, monografia e experimentação de processos alternativos. O grande número de inscritos - 1214 em nove chamadas para bolsas - é uma prova contundente da carência de projetos deste tipo no país. Ao todo, foram distribuídas 51 bolsas para um total de 52 projetos entre 1984 e 1997 (dois deles receberam apenas meia bolsa, em 1992). ${ }^{22}$ Além do Marc Ferrez, a Funarte instituiu o Prêmio Nacional de Fotografia, a partir de 1995. Durante quatro edições, a cada ano foram homenageados sete pessoas, nas categorias fotógrafo jovem, publicação, texto, arte, fotojornalismo e fotodocumentação, fotografia aplicada e contribuição à fotografia brasileira.

Outra fonte de funcionamento a trabalhos autorais importantíssima foi a bolsa de fotografia da Fundação Vítae, uma sociedade civil sem fins lucrativos de apoio a projetos nas áreas da cultura, educação e promoção social. Sediada em São Paulo, a Vítae é mantida pela Fundação Lampadia, constituída em 1985 com capital proveniente da venda das empresas do grupo Hochschild..$^{23}$ A bolsa de artes foi concebida a partir do modelo das bolsas Guggenheim, e desde 1986 financiou projetos de criação artística e de pesquisa histórica ou estética em literatura, artes visuais, música, teatro, cinema, vídeo, fotografia e dança. Ao longo dos 16 anos de existência, 52 fotógrafos receberam a Bolsa Vítae de Fotografia. Somando os projetos contemplados com o Prêmio Marc Ferrez de Fotografia com a bolsa Vítae vemos que, entre 1984 e 2004, cento e quatro projetos de fotógrafos receberam financiamento no país.

A chamada Lei Sarney, de 1985, também foi instrumento importante para a fotografia brasileira. A lei foi modificada no governo Collor, mas ainda hoje continua isentando parte dos impostos das empresas que financiam projetos na área da cultura. A lei federal foi seguida em muitos estados e capitais do país e, apesar de inúmeras distorções, deu frutos significativos. Um deles foi a criação de institutos culturais e fundações dentro de empresas, que passaram a investir em acervos e promoção da fotografia. Um dos mais importantes é o Instituto Moreira Salles, do Unibanco, que hoje possui o maior acervo privado de fotografias do país. O Instituto Cultural Itaú é outro importante incentivador da fotografia. Além de promover exposições, e apoiar

22 Infoto, Funarte. Concurso Marc Ferrez de Fotografia. Sem datação nem autoria.

23 VÍTAE. Relatório 1994 / 95. Sem paginação nem autoria. 
o Mês internacional da fotografia, promovido desde 1993 pelo Nafoto, criou, em 1991, o Setor História da Fotografia no Brasil, de criação e organização de um banco de dados que depois foi incorporado à sua enciclopédia digital sobre artes visuais no Brasil. Atualmente, grande número de fotógrafos atuantes do Brasil tem obras e bibliografias disponíveis em sua Enciclopédia de Artes Visuais, para consulta via Internet.

As leis de incentivo à cultura também facilitaram a parceria entre empresas e museus, inclusive na criação de acervos fotográficos. Um dos mais importantes é o acervo de fotografias do MASP, construído com o patrocínio da Pirelli desde 1990. Além do acervo, todos os anos é editado um catálogo de qualidade em que é reproduzido a totalidade das obras adquiridas durante o ano. Outra parceria entre museu e empresa privada existiu no Rio de Janeiro, onde o Museu de Arte Contemporânea estabeleceu uma parceria da White Martins para a construção de seu acervo fotográfico, centrado principalmente na fotografia feita no século XIX.

Muitas vezes com o apoio das leis de incentivo, empresas compram trabalhos de fotógrafos, para editá-lo como livro, geralmente para ser distribuído como presente de fim de ano a seus clientes preferenciais. 0 que percebemos até agora é que as leis de incentivo à cultura são utilizadas na maioria das vezes para o apoio à publicações de fotógrafos já consagrados e com temas mais palatáveis, o que não acontecia com o Prêmio Marc Ferrez e com a bolsa Vítae, cuja extinção certamente causará um impacto negativo no desenvolvimento de trabalhos autorais.

Nos últimos anos, além de empresas, algumas Organizações Não Governamentais (ONGs) nacionais e estrangeiras também vêem financiando a publicação de livros de fotografia, se adequados às suas preocupações. Há ainda o caso da ONG Imagens da terra - centro de documentação e imagem do trabalhador, criada pelo fotógrafo João Roberto Ripper, que se especializou na produção de fotografias para auxiliar os movimentos sociais e de trabalhadores.

Estas bolsas e leis de incentivo, tanto à produção quanto à divulgação dos trabalhos dos fotógrafos, geraram um número expressivo imagens sobre o país, além de terem servido para divulgar trabalhos feitos antes dos anos de 1980, mas que ainda não haviam conseguido ser editados. Mais de 131 livros de fotografia (excluindo os com objetivo claramente turístico) foram editados no Brasil entre 1985 e 1998. Esta foi uma tremenda mudança, pois entre 1950 e 1979 foram publicados cerca de 39. O quadro começara a ser alterado com a publicação de livros editados por fotógrafos e por empresas privadas que, entre 1980 e 1984, lançaram cerca de 36. ${ }^{24}$ Mas a qualidade das publicações lançadas após

24 Sobre o assunto ver, COELHO, Maria Beatriz R. de V. Imagens da Nação. São Paulo/ Belo Horizonte: Edusp/ Editora UFMG. (no prelo). 
a promulgação das leis de incentivo - muito superiores aos publicados por autores independentes - é uma prova contundente dos efeitos das leis sobre o mercado editorial.

\section{Considerações finais}

O campo da fotografia profissional passou por várias mudanças durante o período abordado por este artigo. Se até meados do século prevaleceu o que Boris Kossoy chamou de olhar estrangeiro sobre o país, ${ }^{25}$ desde os anos de 1970 passamos a ser retratados na maioria das vezes a partir das câmaras de brasileiros, muitos deles com nível universitário e exercendo a profissão em redações de jornais e revistas, nas agências de fotógrafos ou de publicidade. Se por um lado, procuram apontar problemas, denunciar as mazelas do país, por outro têm uma preocupação de nos mostrar em toda a nossa diversidade. A vida dos povos ribeirinhos da Amazônia, os quilombolas, as festas populares, a riqueza da natureza, a religiosidade popular, o trabalho infantil, os trabalhadores rurais, os sem-terra, a devastação de nossas matas, aldeias indígenas, a violência e a solidão das grandes cidades e tantos outros assuntos foram e são abordados por estes fotógrafos, que procuram, através das leis de incentivo, conseguir o financiamento para realizar seu trabalho e publicá-lo. A fotografia hoje tem espaço garantido em museus, bienais e galerias de arte. Os fotógrafos, principalmente os documentaristas e os que fazem pesquisas estéticas, têm um status elevado e alguns, como Miguel Rio Branco, Nair Benedicto, Walter Firmo, Araquém Alcântara, Pedro Martinelli, Claudia Andujar, Sebastião Salgado e tantos outros são reconhecidos internacionalmente. Mas, seja qual for o tema, ao analisar fotografias sempre nos deparamos com um olhar construído nas cidades, forjado a partir da experiência de se movimentar no espaço urbano. Mesmo quando os fotógrafos se voltam para o campo, para as aldeias indígenas, seu olhar é impregnado por essa experiência. É por isto que ainda podemos encontrar afinidades entre os olhares dos estrangeiros e os dos brasileiros. E é por isto também que podemos reconhecer marcas desta vivencia ao analisar as fotografias. Mas este é um assunto para um novo artigo.

25 KOSSOY, Boris e CARNEIRO, Maria Luiza Tucci. O olhar europeu: o negro na iconografia brasileira do século XIX. São Paulo: Edusp, 1994. 